\title{
Do cognitively stimulating activities affect the association between retirement timing and cognitive functioning in old age?
}

\author{
Isabel Baumann ${ }^{1,2 *}$ (D), Harpa Sif Eyjólfsdóttir ${ }^{3}$, Johan Fritzell ${ }^{3}$, Carin Lennartsson ${ }^{3}$, \\ Alexander Darin-Mattsson ${ }^{3}$, Ingemar Kåreholt ${ }^{3,4}$, Ross Andel ${ }^{5,6}$, Julia Dratva ${ }^{1,7}$ \\ and Neda Agahi $^{3}$
}

${ }^{1}$ Center for Health Sciences, Zurich University of Applied Sciences, Winterthur, Switzerland, ${ }^{2}$ National Center of Competence in Research, 'Overcoming Vulnerability: Life Course Perspectives', c/o Zurich University of Applied Sciences, Winterthur, Switzerland, ${ }^{3}$ Aging Research Center, Karolinska Institutet and Stockholm University, Stockholm, Sweden, ${ }^{4}$ Institute of Gerontology, School of Health Sciences, Aging Research Network-Jönköping, Jönköping University, Jönköping, Sweden, ${ }^{5}$ School of Aging Studies, University of South Florida, Tampa, Florida, USA, ${ }^{6}$ International Clinical Research Center, St. Anne's University Hospital, Brno, Czech Republic and ${ }^{7}$ Medical Faculty, University of Basel, Basel, Switzerland ${ }^{\star}$ Corresponding author. Email: isabel.baumann@zhaw.ch

(Accepted 22 June 2020; first published online 16 July 2020)

\begin{abstract}
In response to the rising financial pressure on old-age pension systems in industrialised economies, many European countries plan to increase the eligibility age for retirement pensions. We used data from Sweden to examine whether (and if so, how) retirement after age 65 - the eligibility age for basic pension-compared to retiring earlier affects older adults' (between ages 70 and 85 ) cognitive functioning. Using a propensity score matching (PSM) approach, we addressed the selection bias potentially introduced by non-random selection into either early or late retirement. We also examined average and heterogeneous treatment effects (HTEs). HTEs were evaluated for different levels of cognitive stimulation from occupational activities before retirement and from leisure activities after retirement. We drew from a rich longitudinal data-set linking two nationally representative Swedish surveys with a register data-set and found that, on average, individuals who retire after age 65 do not have a higher level of cognitive functioning than those who retire earlier. Similarly, we did not observe HTEs from occupational activities. With respect to leisure activities, we found no systematic effects on cognitive functioning among those working beyond age 65 . We conclude that, in general, retirement age does not seem to affect cognitive functioning in old age. Yet, the rising retirement age may put substantial pressure on individuals who suffer from poor health at the end of their occupational career, potentially exacerbating social- and health-related inequalities among older people.
\end{abstract}

Keywords: retirement timing; retirement policy; health outcomes; cognition; occupational activities; leisure activities; propensity score matching

(C) The Author(s), 2020. Published by Cambridge University Press. This is an Open Access article, distributed under the terms of the Creative Commons Attribution licence (http://creativecommons.org/licenses/by/4.0/), which permits unrestricted re-use, distribution, and reproduction in any medium, provided the original work is properly cited. 


\section{Introduction}

In light of the rising life expectancy and associated financial pressure on old-age pension systems in industrialised economies, many Organisation for Economic Co-operation and Development (OECD) countries have increased or plan to increase the eligibility age for retirement pensions (OECD, 2013: 55). In this context, it is of interest whether - and if so, how - an extension of working life affects older people's health in the years after retirement. In this study, we focused on cognitive functioning as a health outcome. Put simply, there exist two hypotheses about the potential effects of working life extension on cognitive functioning in old age: on the one hand, the 'wear and tear' hypothesis claims that engaging in stressful activities, such as working under time pressure, can have harmful effects (Case and Deaton, 2005: 202; Reeuwijk et al., 2013: 6). This perspective suggests that later retirement leads to worse health outcomes than earlier retirement. On the other hand, the 'use it or lose it' hypothesis states that engaging in cognitively stimulating activities, such as an interesting occupation, translates into positive health outcomes later (Corcoran, 1991: 538; Everard et al., 2000: S211; Nexø et al., 2016; Xue et al., 2017). Under this assumption, later retirement leads to better health outcomes than earlier retirement.

The previous findings on the effect of the extension of working life on individuals' cognition are inconsistent. One of the reasons for these differing results may be heterogeneity in the study samples with respect to the specific occupational or socio-economic groups examined. In fact, a number of studies have suggested that the effect of working life extension on cognition is mediated by the characteristics of an individual's job, which is highly dependent on socio-economic status (Schooler et al., 1999; Andel et al., 2005, 2007; Karp et al., 2009; Ihle et al., 2016). In addition, the divergent results in the extant literature may be due to the application of different methodological approaches.

As the timing of retirement is an endogenous phenomenon, such that individuals who retire early tend to be fundamentally different from those who retire late, it is important to address selection bias (Bender, 2012; Iparraguirre, 2014). For instance, workers in poor health tend to retire early, while healthier workers tend to continue to work, a phenomenon referred to as the 'healthy worker effect' (Austen and Ong, 2010). Most previous studies addressing selection bias have used an instrumental variable method (Rohwedder and Willis, 2010; Bonsang et al., 2012; Mazzonna and Peracchi, 2012, 2017; Nishimura et al., 2018). Since we cannot conclusively assess whether an instrumental variable is appropriate (Antonakis et al., 2010: 1103), there is a need to examine how retirement timing affects cognitive functioning in old age with other methodological approaches.

In the present study, therefore, we addressed the problem of endogeneity by using a propensity score matching (PSM) approach. To our knowledge, few studies examining the effect of retirement timing used a matching method to better approximate with a causal approach (Behncke, 2012; Eyjólfsdóttir et al., 2019). Those studies that did use a matching method focused not on cognition, but rather on the outcome of general health status in old age. Therefore, our study fills a gap in the literature and contributes to a better approximation of a causal analysis of the timing of retirement on cognitive functioning between the ages of 70 and 85 . 
Furthermore, we explored whether this effect varies by level of engagement in stimulating occupational activities and leisure activities after retirement.

\section{Earlier research findings}

\section{Self-selection into early or late retirement}

An extensive body of literature has been dedicated to the question of how individuals decide when to retire - provided that they have the option to choose. This literature on retirement timing has mainly focused on early or late retirement. One of the drivers of self-selection into early retirement is adverse health conditions. A study from Canada showed that individuals' health status strongly affected their decision to retire (Schirle, 2010: 523). Poor health often forces older workers out of employment earlier than they had planned, as shown by a study from Norway (Solem et al., 2016). Compared to individuals with a good self-reported health status, individuals with a poor health status have a 24 per cent higher probability of entering retirement early. A study on the transition from full-time employment to non-employment among older men in the United States of America (USA) observed that poor health was a much stronger predictor of this transition than reaching the eligibility age for social security benefits or experiencing large wage changes (Blau, 1994). Further, an analysis of longitudinal data from the Whitehall II study on British civil servants found that poor mental health was associated with an increased likelihood of early retirement, while poor mental and physical health was associated with a greater likelihood of disability retirement (Jokela et al., 2010).

Another factor that increases the probability of early entry into retirement is adverse working conditions. A study based on Norwegian register data found an association between hard physical work and disability retirement (Blekesaune and Solem, 2005: 14). The authors suggested that this finding may be explained by one of two different mechanisms: first, individuals with health problems select themselves out of physically demanding jobs into disability retirement because they experience more difficulties carrying out such jobs than individuals in good health; second, jobs involving strenuous work may have a negative effect on workers' health status and may thus reduce their ability to work. Another study based on data from the US National Longitudinal Survey found that individuals who worked in jobs with low substantive complexity (i.e. jobs entailing repetitive and mundane tasks) had a higher risk of exiting the labour market early (Hayward et al., 1998: 98). The authors explained this finding by arguing that occupations that are relatively tedious and provide little autonomy offer no incentive for workers to remain in the labour force. This finding is in line with the results of a study based on longitudinal data from England showing that low job resources (e.g. low decision authority or low recognition) was associated with early exit from employment into retirement. The authors also found an association between high psycho-social demand at work (e.g. high time pressure and working speed) and early exit (Carr et al., 2016).

In addition, individuals' financial situation seems to affect their retirement timing. With respect to financial assets, public policies determining the amount 
of old-age pension and the volume of private savings are important. One study found that the higher the replacement rate of old-age pension (i.e. the share of preretirement earnings replaced by old-age pension), the more likely individuals are to retire early (Henkens, 1999: S67). A study from Switzerland observed that individuals with non-standard occupational careers - particularly those who experienced career interruptions due to child care or who worked part-time, predominantly women - were more likely to retire late (i.e. to work beyond statutory retirement age) than those without such career interruptions (Madero-Cabib et al., 2016: 46).

Madero-Cabib et al. (2016) further observed heterogeneity in retirement timing with respect to gender and family situation. This finding is consistent with results from other countries. For instance, a study from Sweden reported that women tend to retire earlier than men, although the differences were small and decreased over time due to women's steadily increasing labour force participation (König and Sjögren Lindquist, 2016: 330). Informal care-giving by older workers - e.g. caring for grandchildren or ageing parents - has been shown to be associated with earlier retirement (Kridahl, 2017; Kridahl and Silverstein, 2020), particularly among women (Le Feuvre et al., 2015). It has also been shown that, among individuals living with a spouse, the decision to retire is often taken together. A study from the Netherlands found that individuals were more likely to retire early if they had a spouse who supported them in this endeavour (Henkens, 1999: S70). This finding holds for both women and men, but the effect was stronger for female spouses supporting their husbands in retiring early. Similarly, based on a survey of Dutch civil servants, Henkens and van Solinge (2002) reported that individuals' retirement timing preferences affected their partners' preferences. Henkens and van Solinge, therefore, concluded that decisions about the timing of retirement are not primarily individual but are instead typically made by households.

\section{Retirement and subsequent cognition}

While in the present study, we examined the effect of retirement timing on cognitive functioning, most previous studies have examined the effect of entering retirement on such functioning. We must, therefore, infer from this literature how differences in retirement timing may affect cognition in old age. To take selection bias into account, we mainly report results from studies that have considered this bias when examining the association between retirement and cognitive functioning in old age. A study using an instrumental variable approach based on the US Health and Retirement Survey (HRS), the Survey on Ageing and Retirement in Europe (SHARE) and the English Longitudinal Study on Ageing (ELSA) found that individuals who retired early were worse off in terms of their cognitive functioning than individuals of the same age who were not yet retired (Rohwedder and Willis, 2010). A second study using data from SHARE for 11 countries and eligibility age for pension benefits as an instrumental variable found that those who retired during the follow-up period exhibited a faster decline in cognitive functioning (Mazzonna and Peracchi, 2012). A third study using six waves of the HRS and, again, eligibility age as the instrumental variable found a negative effect of retirement on cognitive functioning (Bonsang et al., 2012). In other words, retirement induced a decline in cognitive functioning, and individuals who extended their working life experienced 
later cognitive decline than those who retired earlier. As this third study spanned a longer time period than that by Mazzonna and Peracchi (2012), the negative effect of retirement on cognitive functioning seems to be observable not only in the short term, but also in the long term. Most studies taking selection bias into account thus suggest that retirement age is positively associated with cognitive functioning. Yet, a study based on data from SHARE and employing a cutting-edge method including an instrumental variable approach found that individuals who retired earlier performed better on memory tests (Bianchini and Borella, 2016). As such, there is no consensus in the literature thus far regarding the effect of retirement on cognition.

The results cited above refer to the average effect of retirement across all sociodemographic groups. Another strand of the literature shows, however, that retirement has heterogeneous effects on different groups. On the one hand, a study based on longitudinal data from SHARE for 11 countries reported an immediate positive effect of retirement on cognition for individuals who were employed in physically demanding occupations, but no effect for individuals employed in nonphysically demanding jobs (Mazzonna and Peracchi, 2017: 145). In contrast, an analysis based on the Whitehall II study from the United Kingdom found that while before retirement, individuals in higher occupational classes had higher levels of verbal memory and a lower rate of decline than lower occupational classes, the rates of decline after retirement became similar across all occupational classes (Xue et al., 2017). Finally, one study examined the association between retirement timing and cognitive functioning (Coe et al., 2012). This study, using data from the HRS, found a weak positive effect of early retirement on cognitive functioning for blue-collar workers and no effect for white-collar workers. The authors argued that the positive effect of early retirement for blue-collar workers may be explained by these workers' engagement in intellectually stimulating activities after retirement.

Another strand of the literature argues that the complexity of occupational tasks affects individuals' cognitive functioning. The study of work complexity is rooted in the thesis that individuals' occupational experiences have a substantial impact on their psychological functioning (Kohn and Schooler, 1973). This thesis contradicts the view that the correlation between occupation and individuals' psychological functioning comes about uniquely by individuals selecting jobs that meet their values and preferences. Instead, the authors maintained that the association between occupational conditions (particularly intellectual demands) and individuals' psychological functioning is reciprocal (Kohn and Schooler, 1973: 113).

Recent studies, although they have rarely applied study designs allowing for causal inference and have not focused on retirement, have provided substantial support for Kohn and Schooler's (1973) thesis. For instance, using data from the Swedish Panel Study of Living Conditions of the Oldest Old (SWEOLD), two studies observed that individuals conducting complex data work while aged in their late fifties had higher levels of cognition when aged in their eighties (Andel et al., 2007, 2014). Using another Swedish data-set to examine how the level of work complexity in mid-life affects the risk of dementia, Karp et al. (2009) reported a protective effect of work complexity in jobs involving work with data and people. In other words, higher levels of work complexity modulate correspondingly higher 
dementia risk among persons with lower education. In this context, it has been argued that individuals in more complex occupations are able to accumulate higher levels of so-called 'cognitive reserve'. Cognitive reserve represents the sum of the lifetime use of neural networks (Meng et al., 2017). Research has shown that individuals who accumulate higher levels of cognitive reserve tend to experience a slower decline in cognitive functioning once they are no longer exposed to cognitively stimulating activities. If individuals maintain high levels of reserve-enhancing, cognitively stimulating activities into later life, they are less at risk of experiencing dementia (Wang et al., 2017). This finding has been confirmed by the only study (to our knowledge) to use a causal approach to analyse how work complexity mediates the association between retirement timing and cognitive functioning in old age. Based on data from Japan, this study showed that occupations with higher levels of work complexity lead to slower memory loss after retirement (Kajitani et al., 2017).

Heterogeneity among groups may also exist with respect to the level of cognitive stimulation stemming from leisure activities. For instance, an early retirement may provide individuals with spare time to pursue interesting activities that are more stimulating than those of their former occupation. Evidence for this assumption was provided by the above-mentioned study on older people in Sweden, which did not, however, focus on retirement (Andel et al., 2014). The authors found that the cognitive benefit of jobs with high work complexity is conditional on relatively low levels of leisure activity. They concluded that the interaction between work complexity and leisure activity is thus compensatory rather than complementary. In a US study in which people over 64 years of age without dementia were interviewed about their participation in leisure activities, the authors found that a lifestyle characterised by engagement in intellectual and social activities was associated with slower cognitive decline among older people (Scarmeas et al., 2001). Similarly, a study from Switzerland and an international review study found that individuals who engage in leisure activities after retirement scored highest on cognitive functioning tests (Fratiglioni et al., 2004; Ihle et al., 2016). However, none of these studies focused on retirement timing or used a study design that allowed for causal inference.

Based on the previous literature, we proposed the following hypotheses:

- Hypothesis 1: A later retirement is on average associated with better cognitive functioning in old age.

- Hypothesis 2: The effect of retirement timing differs according to the level of cognitive stimulation from occupational activities before retirement. More precisely, individuals in jobs with higher work complexity and workers in higher-skilled occupational groups experience a stronger positive effect of later retirement on cognitive functioning.

- Hypothesis 3: The effect of retirement timing differs according to the level of cognitive stimulation from leisure activities after retirement. More precisely, individuals who participate more often in physical, social and cultural leisure activities experience a weaker negative effect of early retirement on cognitive functioning. 


\section{The Swedish pension system}

The Swedish pension system consists of four tiers: (1) a public pension scheme, consisting of an income pension (1a) and a premium pension (1b); (2) a guaranteed pension; (3) an occupational pension; and (4) a private pension (European Commission, 2018). The income pension (1a) is based on individuals' total lifetime earnings and is also paid on social insurance benefits, such as sickness and parental leave benefits, as well as unemployment benefits (Hagen, 2013). The eligibility age for the income pension was 61 at the time our survey data were collected (OECD, 2015: 352). The premium pension (1b) is also based on lifetime earnings. These funds are placed in a mandatory defined contribution system, and individuals may choose among several hundred funds for their investment (Hagen, 2013; OECD, 2015: 352). The eligibility age for the premium pension was also 61 at the time our survey data were collected (OECD, 2015: 352). The income-tested guaranteed pension provides a basic pension for individuals with no or low levels of income pension. The amount of benefits depends on how long a person has lived in Sweden. To receive the full guaranteed pension, a person must have lived in Sweden for 40 years (Hagen, 2013). The eligibility age for the guaranteed pension is 65 (OECD, 2015: 352). The occupational pension covers nearly 90 per cent of all employees. There are four different occupational schemes, depending on the type of occupation (OECD, 2008: 279, 2015: 354). The eligibility age for the occupational pension is 55. However, these pension benefits are lower if they are withdrawn at age 55 than at age 65 (European Commission, nd). Finally, there are also private pension plans. The eligibility age for this pension is also 55 (European Commission, nd).

The public pension scheme constitutes the core of the Swedish retirement system, as it covers all individuals living in Sweden with a residency of more than three years (OECD, 2019). In addition, the occupational pension scheme covers more than 90 per cent of all employees and thus includes a large share of the Swedish population (OECD, 2019). The higher eligibility age for the public pension schemes and the guaranteed pension - as compared to the eligibility age for the occupational and private pensions - encourages later retirement for individuals covered only by the first and second tiers of the Swedish pension system.

The public pension scheme was substantially reformed in 1994, and these reforms were fully operational by 2003 . One change brought about by the reforms was the abolition of a statutory retirement age $-\mathrm{a}$ system that aims to promote working longer. Income pension (1a) and the premium pension ( $1 \mathrm{~b}$ ) were available from age 61 without a fixed retirement age; the later the withdrawal, the higher the benefits (OECD, 2003; König and Sjögren Lindquist, 2016). A second change was the replacement of a defined benefit system with a defined contribution system (König and Sjögren Lindquist, 2016). A third important change implemented at about the same time was restricted access to disability or unemployment benefits. In the old system, early retirement before the statutory retirement age of 65 was often financed through disability pensions even in the absence of medical reasons (König and Sjögren Lindquist, 2016). Overall, these reforms led to a stronger commodification of the pension system, with pensions depending more on individuals' 
labour-force participation, which theoretically provides an incentive to work longer (König and Sjögren Lindquist, 2016).

\section{Data and methods}

\section{Data}

We drew on three databases linked at the individual level: the Swedish Level of Living Survey (LNU), the SWEOLD, and the Longitudinal Integration Database for Health Insurance and Labour Market Studies (LISA) annual income register. The LNU provided the baseline information, while the SWEOLD provided follow-up information and the LISA was used to identify individuals' retirement age.

The LNU involves a nationally representative random sample of the population aged 15-75 in Sweden. Its participants were initially contacted in 1968 and have since responded to follow-ups in 1974, 1981, 1991, 2000 and 2010. Non-responses have been low, and a random sample of young individuals and immigrants are added to the original sample with each additional wave, ensuring that each wave remains representative of the adult Swedish population (Fritzell and Lundberg, 2007). In this study, we used information from the waves conducted in 1974, 1981, 1991 and 2000. The LNU encompasses rich information on health status, health behaviour and working conditions which affect selection into retirement timing.

The SWEOLD is based on the LNU sample and includes those individuals from the LNU who have passed age 75 (in some waves, passed age 70) and are still living in Sweden. Therefore, one advantage of this data-set is its inclusion of the oldest old. The survey has been carried out in 1992, 2002, 2004, 2011 and 2014. Both the SWEOLD and LNU samples were representative of the entire Swedish population at the time of the interviews. A particularity of the SWEOLD survey is that it includes individuals living in institutions for frail older people, again to achieve representativeness of the Swedish population. The SWEOLD also has high response rates, varying between 84 and 95 per cent. The LNU is based on direct interviews. The default mode in the 2004 and 2014 SWEOLD surveys was a telephone interview, although in the case of cognitively impaired or frail older people, proxy interviews were conducted with close relatives, trustees or health-care personnel (Lennartsson et al., 2014).

The LISA includes individuals older than 16 who are registered in Sweden as of 31 December of each year. The database combines register data from public institutions in education, the labour market and social security. The LISA contains information about the total annual income from employment (including selfemployment and unemployment), and old-age and disability pensions (Statistics Sweden, 2011). These data were used to determine individuals' retirement age.

The data-set for the present study was created based on the SWEOLD waves of 2004 and 2014 (Table 1). Individuals interviewed in SWEOLD 2004 (which we called cohort 1) were linked to the latest available data in the 1974, 1981 or 1991 waves. Individuals interviewed in SWEOLD 2014 (cohort 2) were linked to the latest available data in the 1981, 1991 or 2000 waves. Both cohorts were 
Table 1. Description of data and cohorts

\begin{tabular}{lcccc} 
& & & \multicolumn{2}{c}{ Survey year } \\
\cline { 4 - 5 } Wave & Age & Data & Cohort 1: born & Cohort 2: born \\
range & source & $1920-1934$ & $1929-1944$ \\
\hline$t_{0}$ & $40-71$ & LNU/LISA & $1974,1981,1991$ & $1981,1991,2000$ \\
\hline$t_{1}$ & $70-85$ & SWEOLD & 2004 & 2014 \\
\hline $\begin{array}{l}\text { Number of } \\
\text { observations }\end{array}$ & & & 740 & 721 \\
\hline
\end{tabular}

Notes: $\mathrm{N}=1,461 . t_{0}$ : a point in people's lives before retirement. $t_{1}$ : a point in people's lives after retirement. LNU: Swedish Level of Living Survey. LISA: Longitudinal Integration Database for Health Insurance and Labour Market Studies. SWEOLD: Swedish Panel Study of Living Conditions of the Oldest Old.

complemented with data from the LISA to identify retirement age. The two cohorts were then appended and integrated into a single data-set $(\mathrm{N}=3,166)$. Information for $t_{0}$ - a point in people's lives before retirement - was taken from the LNU survey, and information for $t_{1}$ - a point in people's lives after retirement - was taken from the SWEOLD. As the birth cohorts overlapped, duplicates $(\mathrm{N}=546)$ were identified. Among these duplicates, we kept the observation in which the individual's age was closer to 75 in the SWEOLD and eliminated the other observation. Moreover, we excluded individuals who had nine or fewer years of gainful employment $(\mathrm{N}=245)$ and those for whom a retirement age could not be identified $(\mathrm{N}=$ 523), likely because they were still active in the labour market or had passed away before retirement. This procedure left us with a sample size of 1,852 individuals, of whom 1,461 responded to the SWEOLD survey and were alive when we measured cognitive functioning at $t_{1}$. In the PSM procedure, 506 individuals were not selected, which left us with an analytical sample of 955 individuals (see below for a detailed description). A flowchart of the sample selection process is presented in Figure A1 in the Appendix.

\section{Measures}

Dependent variable

Cognitive functioning (or, in short, cognition) was measured with a subset of the Mini-Mental State Examination (MMSE; Folstein et al., 1975). The original MMSE is a measure of global cognition that is divided into two sections: the first requires vocal responses only and covers orientation, memory and attention, while the second tests the ability to follow verbal and written commands, write a sentence spontaneously and copy a complex polygon similar to a Bender-Gestalt figure. The MMSE has been used in clinical and epidemiological research and has been proven to be both valid and reliable. For the present study, we used an abridged, 11-point version of the MMSE. A validation study showed that the short version was able to assess individuals' cognition in a way comparable to the full version (Ericsson et al., 2017). We measured cognition at one time-point, which was the age at which respondents participated in the SWEOLD survey 
(between ages 70 and 85), controlling for their age and thus considering that the level of cognition tends to decrease with age.

\section{Independent variables}

Our main independent variable was retirement timing. This was a binary variable in which (0) was retiring before or at age 65 and (1) was retiring after age 65 . The cutoff at age 65 was chosen for two reasons. First, this is the age at which the guaranteed pension is available and therefore constitutes the mode category (i.e. the most frequent retirement age in Sweden). Second, this cut-off point has a methodological advantage: to achieve robust results in the PSM analysis, the 'control group' should be larger than the 'treatment group'. This requirement was fulfilled under the chosen condition. We thus defined the treatment group as individuals who retired after age 65. The distribution of retirement age in our sample is shown in Figure 4.

We applied the definition of retirement timing outlined by Eyjólfsdóttir et al. (in press). In a detailed methodological analysis comparing register and survey data, the authors found that this operationalisation of retirement age for register data corresponded most closely to the retirement age of individuals indicated in the survey. According to this operationalisation, retirement timing is identified based on the LISA data and replicates the operationalisation of Stenberg et al. (2012), Svensson et al. (2015) and Eyjólfsdóttir et al. (2019) considering labour income and pension income. Individuals are defined as retired when their pension income exceeds their total annual income from labour earnings. Income from labour consists of individuals' income from employment and self-employment, as well as transfers connected to unemployment and labour market measures. Income from pensions consists of occupational pension, old-age pension, early retirement pension and disability pension.

The variables used for the PSM algorithm were identified based on the LNU survey and measured at $t_{0}$ before retirement. Sex was a dummy variable. Years of education and years of birth were assessed as continuous variables. Cohort indicated the year at which the outcome measure at $t_{1}$ was assessed. Years between pre-retirement measures and retirement was a linear variable and measured the number of years between the measurement of such variables as smoking status or spouse employment status and retirement. Physical inactivity was a binary variable for which (0) was at least once a week and (1) was less than once a week. Smoking status was measured such that (0) was no, (1) was having quit smoking, (2) was fewer than ten cigarettes a day, and (3) was more than ten cigarettes a day. Physician visits indicated the number of visits in the past 12 months. First occupation indicated the first occupation that lasted more than six months and was measured in four categories: unskilled manual, skilled manual, lower non-manual and higher nonmanual. Physical working conditions was measured on a scale from 0 to 19 , where 0 was very easy and 19 was very hard. Job control was measured on a scale from 0 to 3 , where 0 meant high control and 3 meant low control. Job demands were measured on a scale from 0 to 20 , where 0 meant low demands and 20 meant high demands. Substantive complexity is described in more detail below. Mobility limitations was coded as (0) for no limitations, (1) for one limitation, (2) for two limitations, (3) for three limitations and (4) for four or more limitations. Musculoskeletal pain was measured on a scale from 0 to 6 , where 0 was no 
pain and 6 was the highest level of pain. Psychological health was measured on a scale from 0 to 16 , where 0 was no problems and 16 was the highest level of problems. Gastric problems was assessed on a scale from 0 to 7 , where 0 meant no such problems and 7 represented the highest level of problems. Circulatory problems was measured on a scale from 0 to 11 , where 0 meant no problems and 11 represented the highest level of problems. Limited financial resources was examined with the question, 'If a situation suddenly arose in which you had to come up with 12,000 kronor $(\approx € 1,200$ or $\$ 1,300)$ in a week, could you manage it?', where $(0)$ was yes and (1) was no. The amount was adjusted to inflation to represent a similar amount over time. Employment status of spouse was coded as (0) for spouses who had employment activity, (1) for spouses who did not have employment activity and (2) for individuals without a spouse.

Occupational group was based on individuals' main lifetime occupation and was defined as (1) for unskilled manual workers, (2) for skilled manual workers, including small farmers without employees and self-employed workers with no employees, (3) for lower non-manual workers, including farmers with extensive land and/ or employees and self-employed workers with 1-19 employees, and (4) for higher non-manual workers, including both intermediate and higher non-manual workers, free traders with academic occupations and self-employed workers with at least 20 employees (Kåreholt et al., 2011: 68).

Substantive complexity was also based on individuals' main lifetime occupation. Substantive complexity is one of the facets of intellectual demands Kohn and Schooler (1973: 116) identified as most strongly affecting workers' psychological functioning. This measure was later quantified by Miller et al. (1980) through the use of a factor analysis to reduce the large number of worker characteristics included in job descriptions in the US dictionary of occupational titles to eight central characteristics. These eight characteristics were then transformed into an index defined as substantive complexity.

Socialising with friends, family and acquaintances was a measure that combined several survey questions about visits to and from friends, family and acquaintances. It was measured at $t_{1}$ on a four-point scale in which (0) represented a very low level of socialising and (3) represented a very high level of socialising. Participating in cultural activities was a measure that combined several survey questions about such activities as going to the movies, the theatre, concerts, museums and exhibitions, where (1) represented no, (2) represented yes, sometimes and (3) represented yes, often. Does walks and exercises was a binary variable for which (0) was never and (1) was sometimes or often.

An overview of the measures is provided in the descriptive statistics in Table 2.

\section{Analysis}

\section{Propensity score matching}

Since retirement timing is not random but is instead due to, for example, individuals' health status or financial situation, we simulated an experimental situation using a PSM approach, with 'retirement after age 65 ' as the treatment and 'retire-

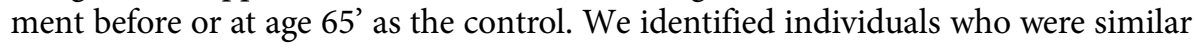


Table 2. Descriptive statistics

\begin{tabular}{|c|c|c|}
\hline & $\%$ or mean $(\mathrm{SD})$ range & $\mathrm{N}$ \\
\hline Cognitive functioning (MMSE) & $9.6(1.6) 0-11$ & 955 \\
\hline \multicolumn{3}{|l|}{ Retirement timing: } \\
\hline After age 65 (treatment group) & 23.9 & 228 \\
\hline Before or at age 65 (control group) & 76.1 & 727 \\
\hline \multicolumn{3}{|l|}{ Substantive complexity in categories: } \\
\hline Very low & 20.0 & 191 \\
\hline Rather low & 36.5 & 349 \\
\hline Rather high & 32.2 & 307 \\
\hline Very high & 11.3 & 108 \\
\hline \multicolumn{3}{|l|}{ Occupational groups: } \\
\hline Unskilled manual workers & 23.1 & 221 \\
\hline Skilled manual workers & 27.5 & 263 \\
\hline Lower non-manual workers & 12.9 & 123 \\
\hline Upper non-manual workers & 36.4 & 348 \\
\hline \multicolumn{3}{|c|}{$\begin{array}{l}\text { Socialising with family, friends and acquaintances in } \\
\text { categories: }\end{array}$} \\
\hline Very low level & 14.0 & 133 \\
\hline Rather low level & 40.8 & 388 \\
\hline Rather high level & 32.6 & 310 \\
\hline Very high level & 12.7 & 121 \\
\hline \multicolumn{3}{|l|}{ Participates in cultural activities: } \\
\hline No & 30.5 & 291 \\
\hline Yes, sometimes & 52.4 & 500 \\
\hline Yes, often & 19.1 & 163 \\
\hline \multicolumn{3}{|l|}{ Does exercises and walks: } \\
\hline No & 13.9 & 133 \\
\hline Yes & 86.1 & 821 \\
\hline \multicolumn{3}{|l|}{ Sex: } \\
\hline Female & 51.0 & 487 \\
\hline Male & 49.0 & 468 \\
\hline Years of education & 10.3 (3.8) 4-34 & 955 \\
\hline Year of birth & $1933(7.0)$ 1920-1944 & 955 \\
\hline \multicolumn{3}{|l|}{ Cohort: } \\
\hline Cohort 1 & 53.9 & 515 \\
\hline Cohort 2 & 46.1 & 440 \\
\hline
\end{tabular}


Table 2. (Continued.)

\begin{tabular}{|c|c|c|}
\hline & $\%$ or mean (SD) range & $\mathrm{N}$ \\
\hline Years between pre-retirement measures and retirement & $5.7(2.6) 1-10$ & 955 \\
\hline \multicolumn{3}{|l|}{ Physical inactivity: } \\
\hline Active at least once a week & 70.3 & 671 \\
\hline Active less than once a week & 29.7 & 284 \\
\hline \multicolumn{3}{|l|}{ Smoking status: } \\
\hline No & 53.2 & 508 \\
\hline Quit & 14.8 & 141 \\
\hline$\geqslant 10$ cigarettes per day & 10.9 & 104 \\
\hline$<10$ cigarettes per day & 21.15 & 202 \\
\hline Physician visits & $1.8(2.8) 0-40$ & 955 \\
\hline \multicolumn{3}{|l|}{ Main lifetime occupation: } \\
\hline Unskilled manual & 55.0 & 525 \\
\hline Skilled manual & 11.5 & 110 \\
\hline Lower non-manual & 18.3 & 175 \\
\hline Upper non-manual & 15.2 & 145 \\
\hline Physical working conditions & $3.3(3.4) 0-17$ & 955 \\
\hline \multicolumn{3}{|l|}{ Job control: } \\
\hline 0 & 28.4 & 271 \\
\hline 1 & 32.6 & 311 \\
\hline 2 & 24.6 & 235 \\
\hline 3 & 14.5 & 138 \\
\hline Job demands & $1.1(0.8) 0-20$ & 955 \\
\hline Substantive complexity & $4.6(2.3) \quad 0.6-10$ & 955 \\
\hline \multicolumn{3}{|l|}{ Mobility limitation: } \\
\hline No limitation & 78.9 & 753 \\
\hline 1 limitation & 12.4 & 118 \\
\hline 2 limitations & 3.4 & 32 \\
\hline 3 limitations & 1.6 & 15 \\
\hline 4 or more limitations & 3.9 & 37 \\
\hline Musculoskeletal pain & $1.4(1.6) 0-6$ & 955 \\
\hline Psychological health & 2.5 (3.1) $0-16$ & 995 \\
\hline Gastric problems & $0.5(1.1) 0-7$ & 955 \\
\hline Circulatory problems & $0.6(1.1) 0-8$ & \\
\hline
\end{tabular}


Table 2. (Continued.)

\begin{tabular}{lcc}
\hline & $\%$ or mean (SD) range & $\mathrm{N}$ \\
\hline Limited financial resources: & & 810 \\
No & 84.8 & 145 \\
\hline Yes & 15.2 & 763 \\
Employment status of spouse: & 79.9 & 143 \\
Active in labour market & 15.0 & 49 \\
\hline Out of labour market & 5.1 & 43.9 \\
Not co-habiting & & \\
\hline
\end{tabular}

Notes: SD: standard deviation. MMSE: Mini-Mental State Examination.

in terms of potential confounding factors in both the treatment group and the control group (Rosenbaum and Rubin, 1985).

We used the nearest neighbour matching algorithm and included the following covariates: sex, years of education, year of birth, cohort, years between pre-retirement variables and retirement, physical inactivity, smoking status, physician visits, occupational group of main lifetime occupation, physical working conditions, job control, job demand, substantive complexity, mobility limitations, musculoskeletal pain, psychological health, gastric problems, circulatory problems, limited financial resources and employment status of the spouse. Our matching analysis reduced the sample size to 955 and yielded a treatment group of 228 individuals and a control group of 727 individuals. As indicated by Figure A2 in the Appendix, the balancing of the covariates was substantially improved through the matching procedure.

A fundamental assumption of the PSM approach is the common independence assumption (CIA; Lechner, 2001). This assumption presumes that the treatment condition is exogenous and that systematic differences in the outcome between the treatment and the control groups are a result of the treatment. Under this assumption, the covariates must be similarly distributed across the two groups. A $t$-test (results upon request) indicated that the unmatched sample systematically differed with respect to some covariates (e.g. years of education). The matching procedure created a matched sample that no longer had systematic differences in the covariates between the treatment and the control groups. The CIA was thus fulfilled.

In addition, the PSM approach requires the provision of so-called 'common support'. This requirement ensures that individuals with the same propensity score can be in either the treatment group or the control group (Caliendo and Kopeinig, 2008: 35). A histogram analysis (Figure A3 in the Appendix) revealed that the overlap between the two groups was large, and that the common support condition was met. The PSM was carried out using the statistical package psmatch2 in Stata (Leuven and Sianesi, 2003).

\section{Treatment effects}

Once the two balanced groups were created, we estimated the average treatment effect on the treated (ATT), which is the mean difference in the outcome measure 
between the treatment and the control groups. The ATT was examined using the statistical package teffects in Stata. However, while the ATT indicates the average treatment effect, it does not consider potential treatment heterogeneity. In a next step, therefore, we examined the heterogeneous treatment effect (HTE; Blundell et al., 2005). On the one hand, we analysed the HTE for different levels of cognitive stimulation from individuals' occupational and leisure activities using the Stata command teffects. On the other, we analysed the HTE for different propensity score strata using the Stata command hte (Xie et al., 2012). The hte command allows for a computation of the interaction between treatment status and the propensity for treatment. Among different hte options, we chose the smoothing-differencing method, which uncovers the heterogeneity pattern as a non-parametric function of the propensity score by fitting separate non-parametric regressions of the dependent variable on the propensity score. The propensity score-specific treatment effects were calculated as the difference between the two non-parametric fits and were plotted in a graph.

\section{Power analysis}

We applied a post-hoc power analysis using the tool $\mathrm{G}^{\star}$ Power to assess the probability of failing to reject false null hypotheses in favour of our hypotheses $(\mathrm{H} 1-\mathrm{H} 3)$ (Cohen, 1977; Mayr et al., 2007). In line with the convention proposed by Cohen (1977), levels of power above 0.8 are defined as acceptable; levels of power above 0.9 are defined as high (results not shown).

\section{Results}

\section{Retirement after age 65 and cognition}

We found an ATT (the difference in the level of cognition between the treatment and control groups) of 0.14 points (compared to 0.17 points in the unmatched sample). In other words, individuals who retired after age 65 had, on average, a cognitive functioning level that was 0.14 points higher at follow-up than the level of those who retired before or at age 65, measured on an 11-point scale. Yet, the difference was not statistically significant. The power analysis for the ATT provided us with a high level of statistical power, which suggests that the chances of rejecting the null hypothesis (i.e. that there is no difference in the level of cognition between those retired and still working) by error are low.

Turning to the HTE analysis, we first present the findings concerning whether occupational activities before retirement affect cognitive functioning in old age. Figure 1a reports the results for different levels of substantive complexity. We found that, for all levels of substantive complexity, there was a slight positive effect of working longer, but it was very small and did not reach statistical significance. The power analysis for levels of substantive complexity indicated a low level of statistical power, which exposes the results to the bias of possibly accepting the null hypothesis when the association between complexity and cognition may in fact be significant. Figure $1 \mathrm{~b}$ reports the results for different occupational groups. Here, the effects varied more strongly among the four occupational groups: we found a positive effect of retiring after age 65 for upper non-manual and unskilled 
(a)

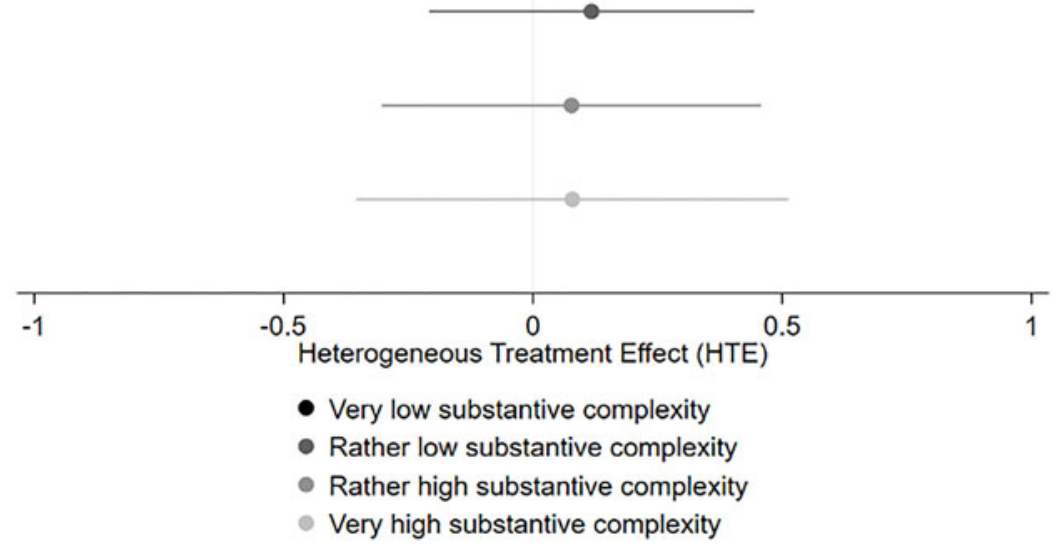

(b)

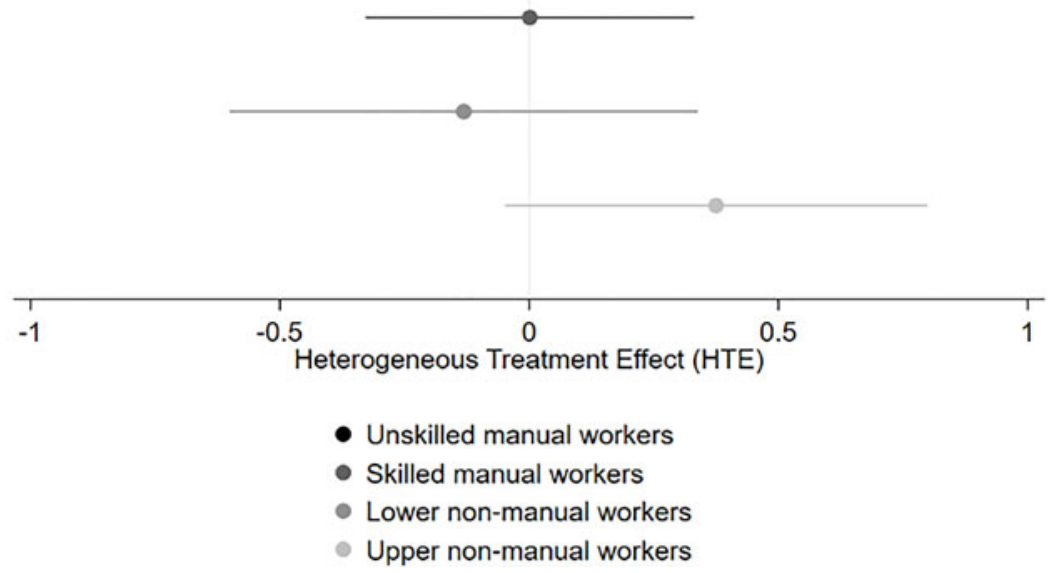

Figure 1. Heterogeneous treatment effects of retiring after age 65 on cognitive functioning in old age by (a) substantive complexity and (b) occupational group.

Note: The dots represent the coefficients and the lines represent the 95 per cent confidence intervals.

manual workers ( 0.37 and 0.34 points, respectively), zero effect for skilled manual workers and a negative effect of -0.13 points for lower non-manual workers. Yet, the effect was not statistically significant for any of the occupational groups. The power analysis for unskilled manual and for upper non-manual workers provided us with a high level of statistical power, which suggests a low likelihood of incorrectly accepting the null hypothesis. The statistical power for the other two groups was too low to allow for an interpretation. 
Second, we present the findings concerning how the level of cognitive stimulation from leisure activities after retirement affects cognitive functioning in old age. Figure 2a reports the results for different levels of socialising with friends, family and acquaintances. We found a negative effect for very low levels of socialising and a positive effect for rather low, rather high and very high levels. Yet, none of the effects were statistically significant. The power analysis for very low levels provided us with an acceptable level of statistical power and the power analysis for rather high levels provided us with a high level of statistical power, which suggests low bias towards accepting the null hypothesis. The statistical power for the other two categories was too low to allow for an interpretation. Figure $2 \mathrm{~b}$ reports the results for different levels of participation in cultural activities. We found that individuals with an intermediate level of participation in cultural activities after retirement in old age experienced a positive effect of retiring after age 65 on cognition (0.4 points). The effect was statistically significant at the $p<0.01$ level. Individuals who did not participate in cultural activities as well as those who often participated in cultural activities experienced a negative effect of working longer, although this effect was not statistically significant. The power analysis for no participation in cultural activities provided us with a high level of statistical power which suggests that the chances of erroneously accepting the null hypothesis are low. The statistical power for frequent participation was too low to allow for an interpretation. Figure $2 \mathrm{c}$ reports the results for different levels of exercising and going for walks. Individuals who did not exercise or go for walks experienced a negative effect of working longer of -0.6 . The effect was statistically significant at the $p<0.01$ level. Those who did exercise and go for walks experienced a positive effect of working longer, although it was not statistically significant. The statistical power for this effect was acceptable which suggests that the chances of accepting the null hypothesis by error were low.

Finally, we present the results of the HTE for the different propensity scores on cognitive functioning. Figure 3 shows that the treatment effect was slightly negative for the lower propensity scores. A negative effect of working longer was thus only present for those individuals who were the least likely to work longer. In other words, individuals who belong to the worker categories that are the least likely to work longer (likely those with adverse health conditions) are those with the highest likelihood of a negative effect if they work longer (e.g. for financial reasons). Yet, again, the results were not statistically significant.

\section{Discussion}

This study examined whether retirement timing affects cognitive functioning in old age. Using a PSM approach, we compared individuals who retired after age 65 with those who retired before or at age 65 . This approach allowed us to reduce the potential selection bias due to non-random selection into either early or late retirement, thereby increasing the possibility of a causal inference being legitimate. We analysed the effect of retiring after 65 first for all individuals in the sample, and then for different sub-groups.

We found that, on average, individuals who retired after age 65 did not have a higher level of cognitive functioning in old age than those who retired earlier. 
(a)

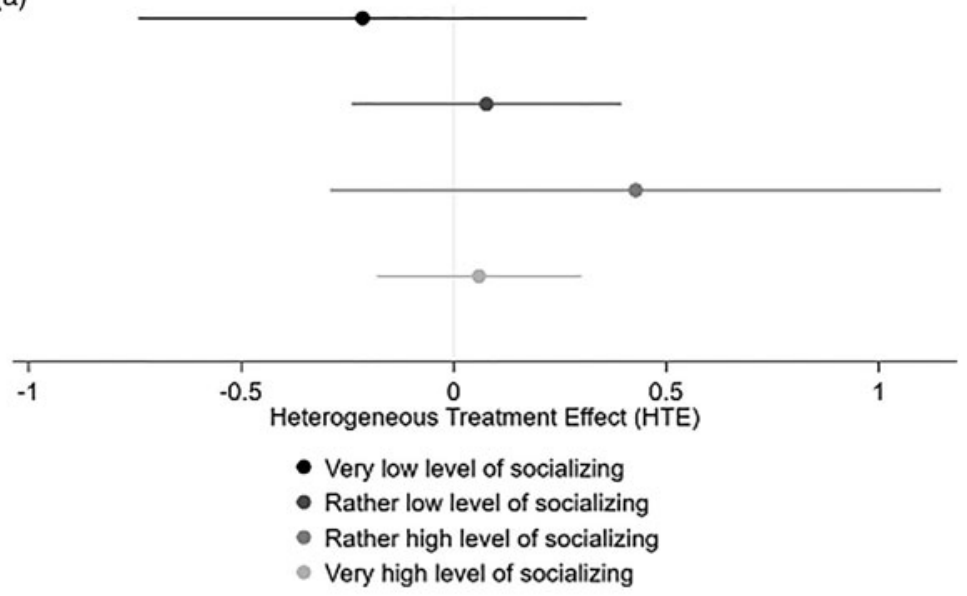

(b)

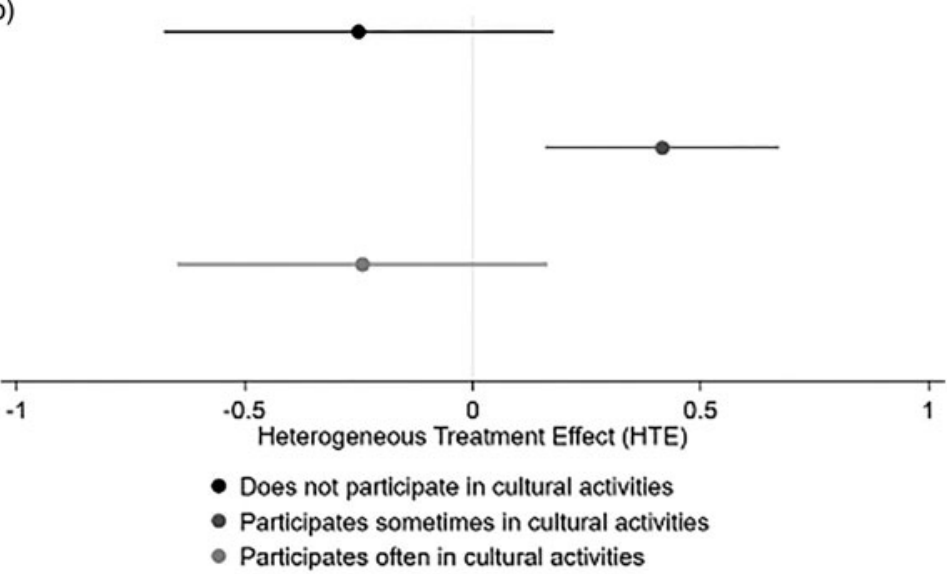

(c)

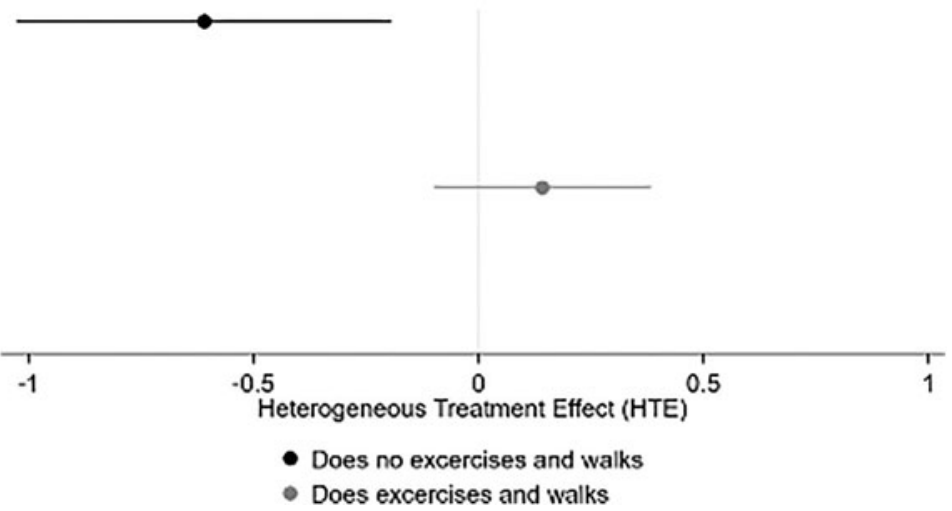

Figure 2. Heterogeneous treatment effects of retiring after age 65 on cognitive functioning in old age by (a) level of socialising with friends, family and acquaintances, (b) participation in cultural activities and (c) doing exercises and walks.

Note: The dots represent the coefficients and the lines represent the 95 per cent confidence intervals. 


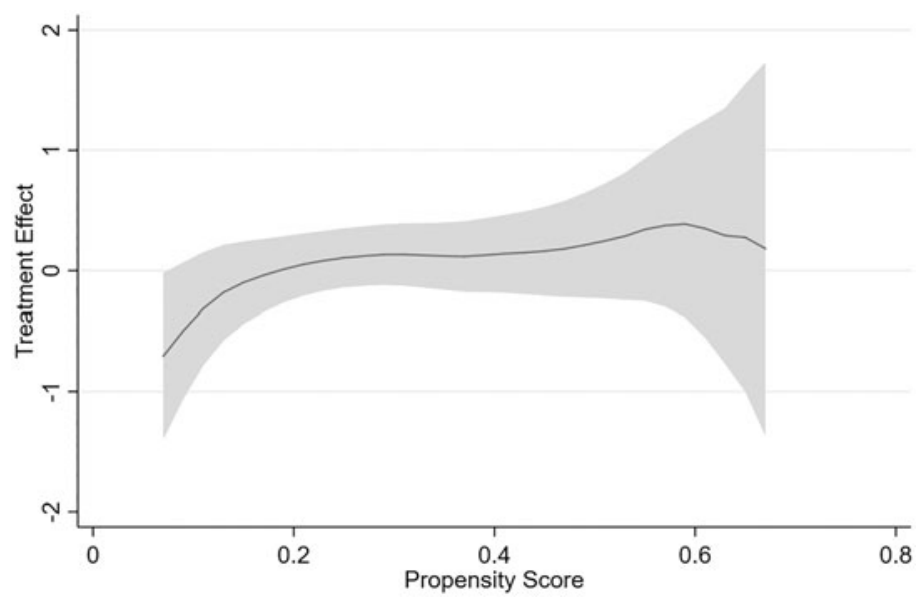

Figure 3. Heterogeneous treatment effect (smoothing-differencing method) of retiring after age 65 on cognitive functioning in old age.

Notes: $\mathrm{N}=955$. The solid line shows the average treatment effect and the shaded area shows the 95 per cent confidence interval.

Similarly, we found that there were no differences in cognitive functioning between the treatment and the control group among unskilled manual and upper nonmanual workers, among individuals with very low levels and rather high levels of socialising, among individuals who did not participate in cultural activities and among those who did exercise and go for walks.

We did, however, find statistically significant effects for single categories. First, we found that individuals who 'sometimes participate in cultural activities' after retirement experienced a higher level of cognitive functioning if they retired after age 65 than if they retired before or at age 65. Second, we found that individuals who 'do not exercise or go for walks' after retirement experienced a lower level of cognitive functioning if they retired after 65 than if they retired before or at age 65.

We can maintain that, although the average effect of working longer went in the direction anticipated in Hypothesis 1, the effect was small, at less than two percentage points. The difference between the two groups was not statistically significant and the power analysis yielded a high level of power, indicating that power was unlikely to affect the acceptance of the null hypothesis. We thus can maintain that our first hypothesis is not supported by our analysis. Similarly, we did not find support for Hypothesis 2, which predicted that individuals in jobs with higher work complexity and workers in higher occupational groups would experience a stronger positive effect of later retirement on cognitive functioning. Yet the power analysis for all work complexity categories and for some occupational groups yielded low levels of power. We therefore cannot say with confidence that Hypothesis 2 should be rejected. We did find, however, some support for Hypothesis 3, which predicted that the effect of retirement timing would differ according to the level of cognitive stimulation from leisure activities after retirement. Yet, we also hypothesised that individuals who engage in leisure activities 


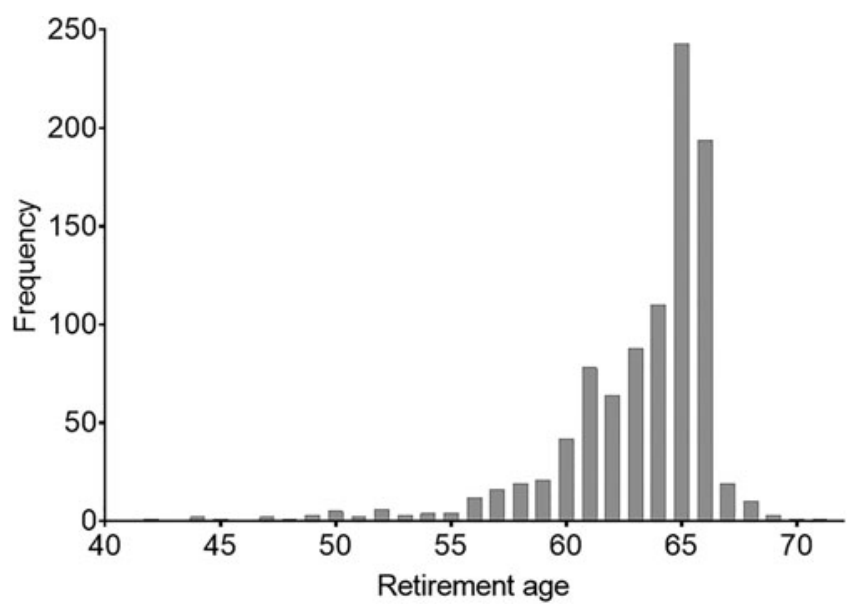

Figure 4. Distribution of retirement age in our sample.

after retirement would experience a weaker negative effect of early retirement on cognitive functioning, which did not correspond to our findings.

Overall, our findings do not support our expectation that retiring later would have a positive effect on cognitive functioning in old age, and that this effect would vary according to the level of participation in cognitively stimulating occupational and leisure activities. A potential explanation for the lack of support for our hypotheses may be that the distribution of our dependent variable was strongly skewed through a ceiling effect of higher levels of cognitive functioning. In fact, methodological studies on the MMSE test have revealed that the test includes several items that are easy to answer, and that ceiling effects are frequent in people with mild cognitive impairment as well as in individuals with high levels of education (Lopez et al., 2005: 142; Franco-Marina et al., 2010: 73). Accordingly, it may have been difficult to identify differences between the treatment and control groups simply because there was little overall variation in cognitive functioning. This is not surprising, given that our study measured cognitive functioning in an age range during which individuals still tend to score highly on the MMSE test, whereas a rapid decline in cognitive functioning has been shown to start after age 84 (Santoni et al., 2015). Moreover, the low variation in cognitive functioning may have been exacerbated by our use of an abridged version of the MMSE instrument (Ericsson et al., 2017).

Another potential explanation for our results may be that our analysis measured long-term effects of retirement timing. In fact, the number of years between individuals' retirement and the measurement of cognitive functioning was between 4 and 30 (mean $=13$, standard deviation $=5.1$ ). An earlier study investigated individuals' cognitive functioning from ages 51 to 75 and compared individuals who retired at age 62 to those who retired at age 65 (Bonsang et al., 2012: 496). The authors reported substantial differences between the two groups in the first years after retirement; however, at age 75 , which was the average follow-up age in our sample, the difference between the two groups was almost zero. 
Our results are not in line with those of earlier research that used a causal approach to study the effect of later retirement on cognitive functioning, which suggested that later retirement is positively associated with better cognitive functioning (Rohwedder and Willis, 2010; Bonsang et al., 2012; Mazzonna and Peracchi, 2012, 2017). Yet, these studies did not specifically examine the effect of retirement timing; rather, they focused on entry into retirement. It is therefore possible that the absence of an effect in our data was because entry into retirement generally leads to a decline in cognitive functioning, independent of the specific timing. Moreover, in contrast to most other previous studies (with the exception of two studies focusing on physical health outcomes: Behncke, 2012; Eyjólfsdóttir et al., 2019), we used a PSM analysis. The divergence of our results from those in the previous literature on the relationship between retirement and cognition may, therefore, be due to the novelty of our methodological approach in the field.

Our study should be viewed in light of the following limitations. The PSM approach only allowed us to control for selection bias due to observable characteristics, not unobservable characteristics (Xie et al., 2012). Our analysis, therefore, may not have considered all relevant factors driving selection bias, such as personality traits or pre-retirement levels of cognitive functioning. Due to our small sample size, our effects had large confidence intervals, meaning that most of our results did not reach statistical significance. The results were based on one follow-up measure of cognition, whereas an assessment of change over time may be preferable. We were particularly careful to include as many known correlates of low cognitive function in middle adulthood as we could, and to use propensity matching to reduce the potential issue of reverse causality. Finally, the dichotomous specification of the treatment in a PSM approach did not allow us to conduct a fine-graded analysis of the effect of different retirement timings on cognitive functioning. Thus, one future research direction may be to distinguish between retirement ages of 58$61,62-65$ and $66-69$.

The strengths of our study are its use of (a) a novel methodological approach, (b) a particularly rich longitudinal data-set linking survey and register data, and (c) a more salient definition of retirement timing. Our contribution to the academic debate thus consists of improving the robustness of research on how retirement timing and cognition are linked. The implications of our study are that there is no clear effect of higher retirement age on cognitive functioning in old age. While earlier studies suggested that a higher retirement age may have positive effects on individuals' short-term cognitive functioning, our analysis did not provide support for a long-term effect of retiring later. Moreover, an increase in retirement age may put substantial pressure on individuals who are already in poor health at the end of their occupational careers or who experience adverse working conditions. It is therefore likely that policies encouraging later retirement would exacerbate social- and health-related inequalities among older people.

\section{Conclusion}

We examined whether later retirement leads to better cognitive functioning between agea 70 and 85 . Using a PSM approach, we found no significant differences between individuals who retired later and those who retired earlier, either 
on average or by different levels of cognitive stimulation from occupational and leisure activities. Our findings suggest, therefore, that retirement age does not affect cognitive functioning between the ages of 70 and 85 .

Supplementary material. The supplementary material for this article can be found at https://doi.org/10. 1017/S0144686X20000847.

Author contributions. All authors have participated in (a) the study conception and design, or the analysis and interpretation of data, (b) the drafting of the article or its critical revision for important intellectual content, and/or (c) approval of the version to be published.

Financial support. This work was supported by the Swiss National Science Foundation (IB; grant number 17492); the research programme 'Social Integration' of Zurich University of Applied Sciences (IB); the Social Inequalities in Ageing (SIA) project, which is funded by NordForsk (HSE, grant number 74637); the Marianne and Marcus Wallenberg (MMW) Foundation (ADM and IK, grant numbers 2011.0036, 2016.0081); and the Swedish Research Council for Health, Working Life, and Welfare (ADM and IK, grant numbers 2019-01100, 2016-00241). The financial sponsors played no role in the design, execution, data analysis and interpretation, nor in the writing of the study.

Conflict of interest. The authors declare no conflicts of interest.

Ethical standards. The Swedish Level of Living Survey (LNU) has an ethical permit (Dnr 2009/1802-31/ 5) from the Regional Ethical Review Board in Stockholm, Sweden. Furthermore, this study has an ethical permit (Dnr 2016/1823-31/5) from the Regional Ethical Review Board in Stockholm, Sweden.

\section{References}

Andel R, Crowe M, Pedersen NL, Mortimer J, Crimmins E, Johansson B and Gatz M (2005) Complexity of work and risk of Alzheimer's disease: a population-based study of Swedish twins. Journals of Gerontology: Psychological Sciences and Social Sciences 60B, P251-P258.

Andel R, Kåreholt I, Parker MG, Thorslund M and Gatz M (2007) Complexity of primary lifetime occupation and cognition in advanced old age. Journal of Aging and Health 19, 397-415.

Andel R, Silverstein M and Kåreholt I (2014) The role of midlife occupational complexity and leisure activity in late-life cognition. Journals of Gerontology: Psychological Sciences and Social Sciences 70B, 314-321.

Antonakis J, Bendahan S, Jacquart P and Lalive R (2010) On making causal claims: a review and recommendations. The Leadership Quarterly 21, 1086-1120.

Austen S and Ong R (2010) The employment transitions of mid-life women: health and care effects. Ageing \& Society 30, 207-227.

Behncke S (2012) Does retirement trigger ill health? Health Economics 21, 282-300.

Bender KA (2012) An analysis of well-being in retirement: the role of pensions, health, and 'voluntariness' of retirement. Journal of Socio-economics 41, 424-433.

Bianchini L and Borella M (2016) Retirement and memory in Europe. Ageing \& Society 36, 1434-1458.

Blau DM (1994) Labor force dynamics of older men. Econometrica 62, 117-156.

Blekesaune M and Solem PE (2005) Working conditions and early retirement: a prospective study of retirement behavior. Research on Aging 27, 3-30.

Blundell R, Dearden L and Sianesi B (2005) Evaluating the effect of education on earnings: models, methods and results from the national child development survey. Journal of the Royal Statistical Society. Series A: Statistics in Society 168, 473-512.

Bonsang E, Adam S and Perelman S (2012) Does retirement affect cognitive functioning? Journal of Health Economics 31, 490-501.

Bonsang E, Adam S and Perelman S (2012) Does retirement affect cognitive functioning? Journal of Health Economics 31, 490-501.

Caliendo M and Kopeinig S (2008) Some practical guidance for the implementation of propensity score matching. Journal of Economic Surveys 22, 31-72. 
Carr E, Hagger-Johnson G, Head J, Shelton N, Stafford M, Stansfeld S and Zaninotto P (2016) Working conditions as predictors of retirement intentions and exit from paid employment: a 10-year follow-up of the English Longitudinal Study of Ageing. European Journal of Ageing 13, 39-48.

Case A and Deaton A (2005) Broken down by work and sex: how our health declines. In Wise D (ed). Analyses in the Economics of Aging, Vol. 1. Chicago, IL: Chicago University Press, pp. 185-214.

Coe NB, von Gaudecker H-M, Lindeboom M and Maurer J (2012) The effect of retirement on cognitive functioning. Health Economics 21, 913-927.

Cohen J (1977) Statistical Power Analysis for the Behavioral Sciences. New York, NY: Academic Press.

Corcoran PJ (1991) Use it or lose it - the hazards of bed rest and inactivity. Western Journal of Medicine 154, 536-538.

Ericsson MC, Gatz M, Kareholt I, Parker MG and Fors S (2017) Validation of abridged mini-mental state examination scales using population-based data from Sweden and USA. European Journal of Ageing 14, 199-205.

European Commission (2018) Pension Adequacy Report 2018, Vol. 2, Country Profiles. Brussels: European Union.

European Commission (nd) Sweden - Old Age Pension. Available at https://ec.europa.eu/social/main.jsp? catId $=1130$ \&langId $=$ en\&intPageId $=4814$.

Everard KM, Lach HW, Fisher EB and Baum MC (2000) Relationship of activity and social support to the functional health of older adults. Journals of Gerontology: Psychological Sciences and Social Sciences 55B, S208-S212.

Eyjólfsdóttir HS, Baumann I, Agahi N, Fritzell J and Lennartsson C (2019) Prolongation of working life and its effect on mortality and health in older adults: propensity score matching. Social Science \& Medicine 226, 77-86.

Eyjólfsdóttir HS, Baumann I, Agahi N and Lennartsson C (in press) How to measure retirement age? A comparison of survey and register data. Journal of Population Ageing. https://doi.org/10.1007/s12062019-09254-6.

Folstein MF, Folstein SE and McHugh PR (1975) 'Mini-mental state'. A practical method for grading the cognitive state of patients for the clinician. Journal of Psychiatric Research 12, 189-198.

Franco-Marina F, García-González JJ, Wagner-Echeagaray F, Gallo J, Ugalde O, Sánchez-García S, Espinel-Bermúdez C, Juárez-Cedillo T, Villa Rodríguez MA and García-Peña C (2010) The Mini-Mental State Examination revisited: ceiling and floor effects after score adjustment for educational level in an aging Mexican population. International Psychogeriatrics 22, 72-81.

Fratiglioni L, Paillard-Borg S and Winblad B (2004) An active and socially integrated lifestyle in late life might protect against dementia. Lancet Neurology 3, 343-353.

Fritzell J and Lundberg $\mathbf{O}$ (2007) Health Inequalities and Welfare Resources: Continuity and Change in Sweden. Bristol, UK: Policy Press.

Hagen J (2013) A history of the Swedish pension system. Uppsala Center for Fiscal Studies, Uppsala, Sweden, Working Paper 7. Available at http://uu.diva-portal.org/smash/get/diva2:621560/FULLTEXT01.pdf.

Hayward MD, Friedman S and Chen H (1998) Career trajectories and older men's retirement. Journals of Gerontology: Psychological Sciences and Social Sciences 53B, 91-103.

Henkens K (1999) Retirement intentions and spousal support: a multi-actor approach. Journals of Gerontology: Psychological Sciences and Social Sciences 54B, S63-S74.

Henkens K and van Solinge H (2002) Spousal influences on the decision to retire. International Journal of Sociology 32, 55-74.

Ihle A, Grotz C, Adam S, Oris M, Fagot D, Gabriel R and Kliegel M (2016) The association of timing of retirement with cognitive performance in old age: the role of leisure activities after retirement. International Psychogeriatrics 28, 1659-1669.

Iparraguirre J (2014) Physical functioning in work and retirement: commentary on age-related trajectories of physical functioning in work and retirement - the role of sociodemographic factors, lifestyle and disease by Stenholm et al. Journal of Epidemiology \& Community Health 68, 493-499.

Jokela M, Head J, Vahtera J, Westerlund H and Marmot MG (2010) From midlife to early old age: health trajectories associated with retirement. Epidemiology 21, 284-290.

Kajitani S, Sakata K and McKenzie C (2017) Occupation, retirement and cognitive functioning. Ageing \& Society 37, 1568-1596. 
Kåreholt I, Lennartsson C, Gatz M and Parker MG (2011) Baseline leisure time activity and cognition more than two decades later. International Journal of Geriatric Psychiatry 26, 65-74.

Karp A, Andel R, Parker MG, Wang H-X, Winblad B and Fratiglioni L (2009) Mentally stimulating activities at work during midlife and dementia risk after age 75: follow-up study from the Kungsholmen Project. American Journal of Geriatric Psychiatry 17, 227-236.

Kohn ML and Schooler C (1973) Occupational experience and psychological functioning: an assessment of reciprocal effects. American Journal of Sociology 38, 97-118.

König S and Sjögren Lindquist G (2016) Sweden: steeply rising older workers' employment rates in a late-exit country. In Hofäcker D, Hess M and König S (eds), Delaying Retirement: Progress and Challenges of Active Aging in Europe, the United States and Japan. London: Palgrave Macmillan, pp. 315-336.

Kridahl L (2017) Retirement timing and grandparenthood in Sweden: evidence from population-based register data. Demographic Research 37, 957-994.

Kridahl L and Silverstein M (2020) Parental survival and retirement timing in the Swedish population. Journal of Population Ageing 13, 81-112.

Lechner M (2001) Identification and estimation of causal effects of multiple treatments under the conditional independence assumption. In Lechner M and Pfeiffer F (eds), Econometric Evaluation of Labour Market Policies. Heidelberg, Germany: Physica/Springer, pp. 43-58.

Le Feuvre N, Kuehni M, Rosende M and Schoeni C (2015) Gendered variations in the experience of ageing at work in Switzerland. Equality, Diversity and Inclusion 34, 168-181.

Lennartsson C, Agahi N, Hols-Salén L, Kelfve S, Kåreholt I, Lundberg O, Parker MG and Thorslund M (2014) Data resource profile: the Swedish Panel Study of Living Conditions of the Oldest Old (SWEOLD). International Journal of Epidemiology 43, 731-738.

Leuven E and Sianesi B (2003) PSMATCH2: Stata module to perform full Mahalanobis and propensity score matching, common support graphing, and covariate imbalance testing. Statistical Software Components S432001, Boston College Department of Economics, revised 01 Feb 2018.

Lopez MN, Charter RA, Mostafavi B, Nibut LP and Smith WE (2005) Psychometric properties of the Folstein Mini-Mental State Examination. Assessment 12, 137-144.

Madero-Cabib I, Gauthier J-A and Le Goff J-M (2016) The influence of interlocked employment-family trajectories on retirement timing. Work, Aging and Retirement 2, 38-53.

Mayr S, Erdfelder E, Buchner A and Faul F (2007) A short tutorial of GPower. Tutorials in Quantiative Methods for Psychology 3, 51-59.

Mazzonna F and Peracchi F (2012) Ageing, cognitive abilities and retirement. European Economic Review 56, 691-710.

Mazzonna F and Peracchi F (2017) Unhealthy retirement? Journal of Human Resources 52, 128-151.

Meng A, Nexø MA and Borg V (2017) The impact of retirement on age related cognitive decline - a systematic review. BMC Geriatrics 17, 160.

Miller AR, Treiman DJ, Cain PS and Roos P (eds) (1980) Work, Jobs, and Occupations: A Critical Review of the Dictionary of Occupational Titles. Washington, DC: National Academy Press.

Nexø MA, Meng A and Borg V (2016) Can psychosocial work conditions protect against age-related cognitive decline? Results from a systematic review. Occupational and Environmental Medicine 73, 487-496.

Nishimura Y, Oikawa M and Motegi $\mathbf{H}$ (2018) What explains the difference in the effect of retirement on health? Evidence from global aging data. Journal of Economic Surveys 32, 792-847.

Organisation for Economic Co-operation and Development (OECD) (2003) Ageing and Employment Policies: Sweden. Development. Paris: OECD Publishing.

Organisation for Economic Co-operation and Development (OECD) (2008) Pension country profile: Sweden. In OECD Private Pensions Outlook 2008. Paris: OECD Publishing, pp. 278-282.

Organisation for Economic Co-operation and Development (OECD) (2013) Health at a Glance 2013: OECD Indicators. Paris: OECD Publishing.

Organisation for Economic Co-operation and Development (OECD) (2015) Pensions at a Glance 2015: $O E C D$ and G20 Indicators. Paris: OECD Publishing.

Organisation for Economic Co-operation and Development (OECD) (2019) Country Profiles - Sweden. Paris: OECD Publishing. Available at https://www.oecd.org/els/public-pensions/PAG2019-country-profile-Sweden.pdf. 
Reeuwijk KG, De Wind A, Westerman MJ, Ybema, JF, Van Der Beek AJ and Geuskens GA (2013) 'All those things together made me retire': qualitative study on early retirement among Dutch employees. BMC Public Health 13, 516.

Rohwedder S and Willis RJ (2010) Mental retirement. Journal of Economic Perspectives 24, 119-138.

Rosenbaum PR and Rubin DB (1985) Constructing a control group using multivariate matched sampling methods that incorporate the propensity score. The American Statistician 39, 33-38.

Santoni G, Angleman S, Welmer A-K, Mangialasche F, Marengoni A and Fratiglioni L (2015) Age-related variation in health status after age 60. PLOS ONE 10, e012007. doi: 10.1371/journal. pone.0120077.

Scarmeas N, Levy G, Tang M-X, Manly J and Stern Y (2001) Influence of leisure activity on the incidence of Alzheimer's Disease. Neurology 57, 2236-2242.

Schirle T (2010) Health, pensions, and the retirement decision: evidence from Canada. Canadian Journal on Aging/La Revue canadienne du vieillissement 29, 519-527.

Schooler C, Mulatu MS and Oates G (1999) The continuing effects of substantively complex work on the intellectual functioning of older workers. Psychology and Aging 14, 483-506.

Solem PE, Syse A, Furunes T, Mykletun RJ, Lange ADE, Schaufeli W and Ilmarinen J (2016) To leave or not to leave: retirement intentions and retirement behaviour. Ageing \& Society 36, 259-281.

Statistics Sweden (2011) Longitudinal Integration Database for Health Insurance and Labour Market Studies. Stockholm: Statistics Sweden.

Stenberg A, de Luna $\mathbf{X}$ and Westerlund $\mathbf{O}$ (2012) Can adult education delay retirement from the labour market? Journal of Population Economics 25, 677-696.

Svensson I, Lundholm E, De Luna X and Malmberg G (2015) Family life course and the timing of women's retirement - a sequence analysis approach. Population, Space and Place 21, 856-871.

Wang H, Macdonald SWS, Dekhtyar S and Fratiglioni L (2017) Association of lifelong exposure to cognitive reserve-enhancing factors with dementia risk: a community-based cohort study. PLOS Medicine 14, e1002251.

Xie Y, Brand JE and Jann B (2012) Estimating heterogeneous treatment effects with observational data. Sociological Methodology 42, 314-347.

Xue B, Cadar D, Fleischmann M, Stansfeld S, Carr E, Kivimäki M, McMunn A and Head J (2017) Effect of retirement on cognitive function: the Whitehall II cohort study. European Journal of Epidemiology 33, 989-1001.

Cite this article: Baumann I, Eyjólfsdóttir HS, Fritzell J, Lennartsson C, Darin-Mattsson A, Kåreholt I, Andel R, Dratva J, Agahi N (2022). Do cognitively stimulating activities affect the association between retirement timing and cognitive functioning in old age? Ageing \& Society 42, 306-330. https://doi.org/ $10.1017 /$ S0144686X20000847 